\title{
Cellular apoptosis and nitric oxide production in PBMC and spleen from dogs with visceral leishmaniasis
}

\author{
Cleber Costa de Martini, Jéssica Thomé de Andrade, Stéfani Karin Martiniano de Almeida, \\ Kathlenn Liezbeth Oliveira Silva, Flavia de Rezende Eugenio, Paulo Sergio Patto dos Santos, \\ Valéria Marçal Felix de Lima* \\ Department of Clinical Care, Surgery and Animal Reproduction, Laboratory of Cellular Immunology, Faculty of Veterinary Medicine of Araçatuba, Universidade Estadual \\ Paulista, "Julio de Mesquita Filho", FMVA/UNESP, Rua Clovis Pestana, 793, Araçatuba, São Paulo, CEP 16050-680, Brazil
}

\section{A R T I C L E I N F O}

\section{Keywords:}

Flow cytometry

Zoonosis

Canis familiaris

Macrophages

Cellular immunity

Visceral leishmaniasis

Apoptosis

Nitric oxide

CD14

Parasite load

\begin{abstract}
A B S T R A C T
Nitric oxide (NO) is involved in the death of the Leishmania parasite and regulation of apoptosis. We quantified the frequency of cells producing NO and its levels in the peripheral blood mononuclear cells (PBMC), leukocytes from spleen in Visceral Leishmaniasis (VL) symptomatic dogs and correlated NO levels with apoptosis and parasite load in the spleen. The percentage of $\mathrm{NO}+$ cells and CD14+/NO + was higher in PBMC and spleen cells in infected dogs than in controls. The levels of $\mathrm{NO}+$ and $\mathrm{CD} 14+/ \mathrm{NO}+$ cells was higher in PBMC, but lower spleen of dogs infected than compared to control. Late apoptosis rates increased in PBMC and spleen of infected dogs compared to controls, and the NO levels and apoptosis not showed correlation. There was a positive correlation between the percentage of cells producing NO in the spleen and parasite load. The NO participates in the immune response in the canine VL, but it is not apoptosis inducer.
\end{abstract}

\section{Introduction}

There is a high worldwide mortality rate caused by VL with approximately 350 million people in 98 countries at risk of infection [1]. Human cases of VL in the Americas, are present in 12 countries; however, $96 \%$ of the cases are reported in Brazil. [2]. VL or kala-azar is a zoonotic disease transmitted to mammals by parasites of the genus Leishmania [3]. Transmission of Leishmania between vertebrate hosts in the New World is by the bite of the blood-sucking sandfly Lutzomyia spp [4].

In the urban environment, dogs are considered the main reservoir for the parasite that causes VL and are important in maintaining the epidemiological cycle of the disease because: a) VL is more prevalent in the canine population than in humans, b) infection in humans is usually preceded by canine cases, and c) dogs have a higher amount of parasites in the skin than men, which favors the infection of vectors [5]. The prevalence of leishmaniasis in dogs in endemic areas can reach $20 \%$ to $40 \%$ of the population [6], and in 2016 this prevalence of canine leishmaniasis was $12.7 \%$ of the total population of dogs in this study area [7].

In dogs, $\mathrm{VL}$ is a systemic disease and can be fatal if left untreated as the host fails to mount an effective protective response against the parasite. Infection spreads in the body of the host via the lymphatic system or becomes blood-borne reaching organs, such as the spleen, lymph nodes, liver and bone marrow, which is rich in mononuclear phagocytes [3].

Dogs with VL exhibit high T-cell apoptosis rates in the peripheral blood and spleen [8]. In healthy mononuclear cell cultures infected with Leishmania infantum a gradual increase in apoptosis was observed in $\mathrm{CD}^{+}, \mathrm{CD}^{+}{ }^{+}$and $\mathrm{CD}^{+}{ }^{+} \mathrm{T}$ cells [9]. In canine $\mathrm{VL}$, the low cellular immune response most likely reflects the depletion of $\mathrm{T}$ cells observed in dogs that had high parasitism in the spleen [10]. Immunosuppression associated with chronic infection occurs due to high rates of apoptosis of T cells, and this mechanism could contribute to the disruption of the white pulp of the spleen and decreased levels of $\mathrm{T}$ cells in the peripheral blood. [6]

In infected dogs, protective immunity has generally been associated with cellular immune responses, characterized by high proportions of $\mathrm{CD}^{+} \mathrm{T}$ cells and CD21 ${ }^{+} \mathrm{B}$ cells [11,12]. High expression levels of IFN$\gamma$, TNF- $\alpha$ and IL-12 [13]. and increased NO were associated with the microbicidal function of which has been demonstrated in vitro [14].

In canine VL, NO is increased in macrophage culture supernatant from asymptomatic dogs in relation to the symptomatic group [15], suggesting that it controls the parasitic load. In addition to functioning

\footnotetext{
* Corresponding author.

E-mail address: vmflima@fmva.unesp.br (V.M.F. de Lima).
} 

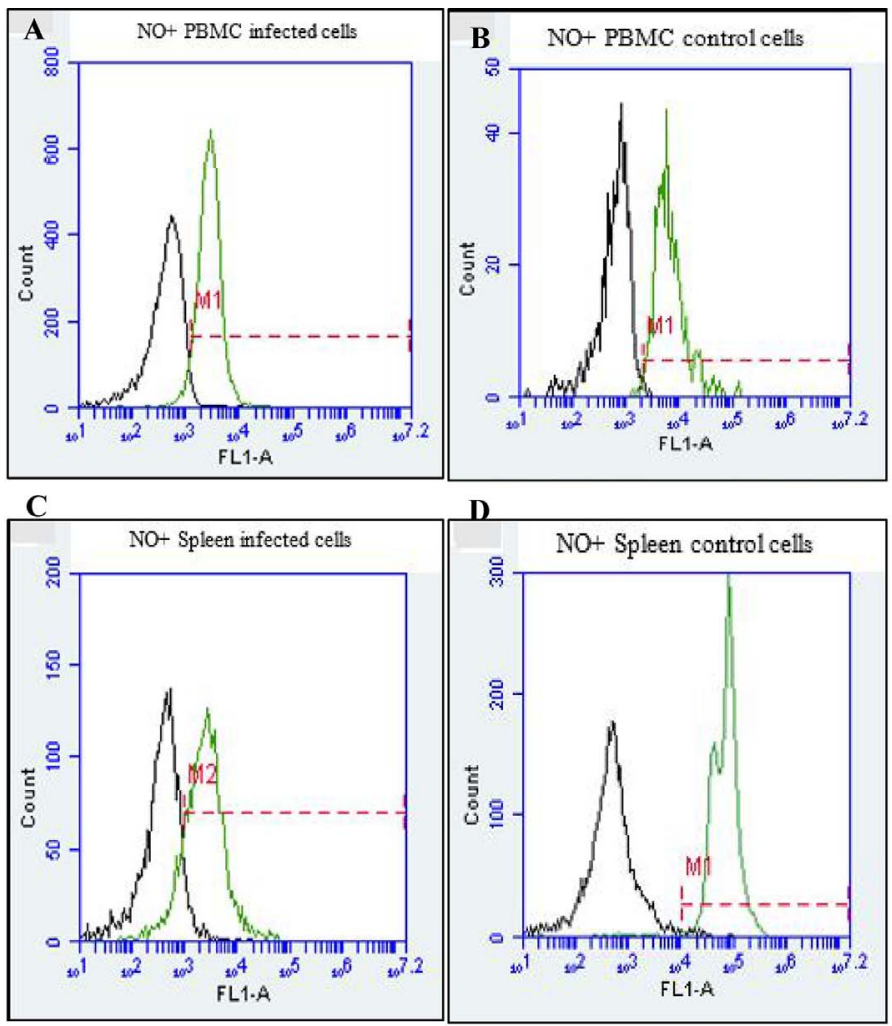

D
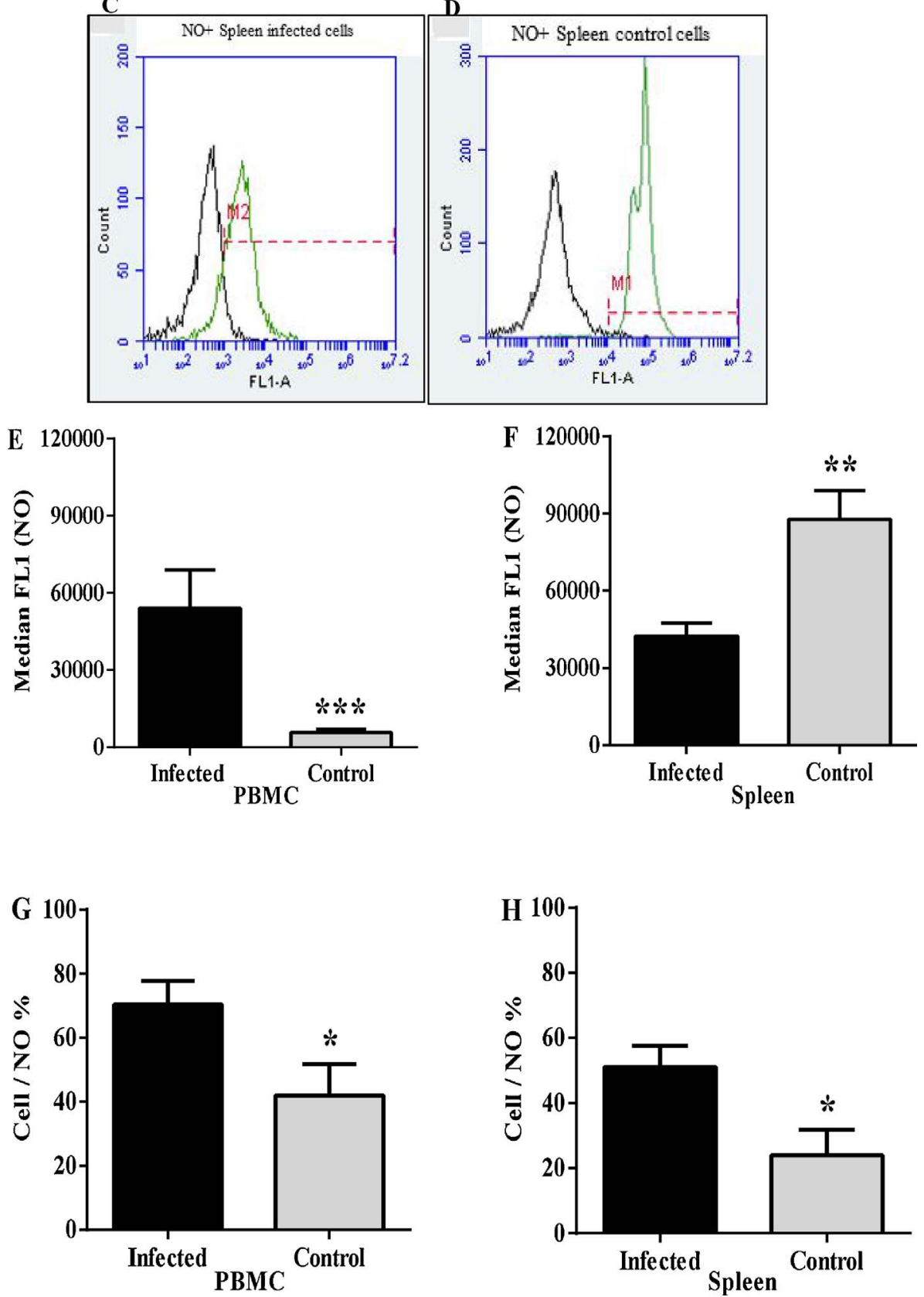

Fig. 1. Overlay histogram shows a representative example of the non-stained cells (dark), NO + labeled (green) from PBMC (A, B), and splenic (C, D) of canine infected and control. Median of NO+ in PBMC (E) and spleen (F) cell. The mean and standard error of mean (SEM) are shown (*). Percentage of NO+ producing cells in PBMC (G) and the spleen $(\mathrm{H})$ of dogs with VL and the control group. Amount of $\mathrm{NO}+$ produced by PBMC and the leukocytes from splenic cells of dogs positive for VL and the control group. Data were analyzed using the Mann-Whitey test $(* P<0.05)$. (Infected - black bars), (Control - gray bars). (For interpretation of the references to colour in this figure legend, the reader is referred to the web version of this article.) as a microbicide, the NO may be involved in the immunopathology of the disease because in different parasitic infections its overproduction is associated with the absence of a lymphocyte response and apoptosis in different cell types [16]. NO can induce apoptosis in response to inflammatory reactions by different pathways inhibiting respiration of mitochondria to release cytochrome $\mathrm{c}$ that activates caspases, or by activating protein kinases, p38, MAPK, Janus kinase e ERK 1 and 2, leading to pro apoptotic signals, with accumulation of p53 and 

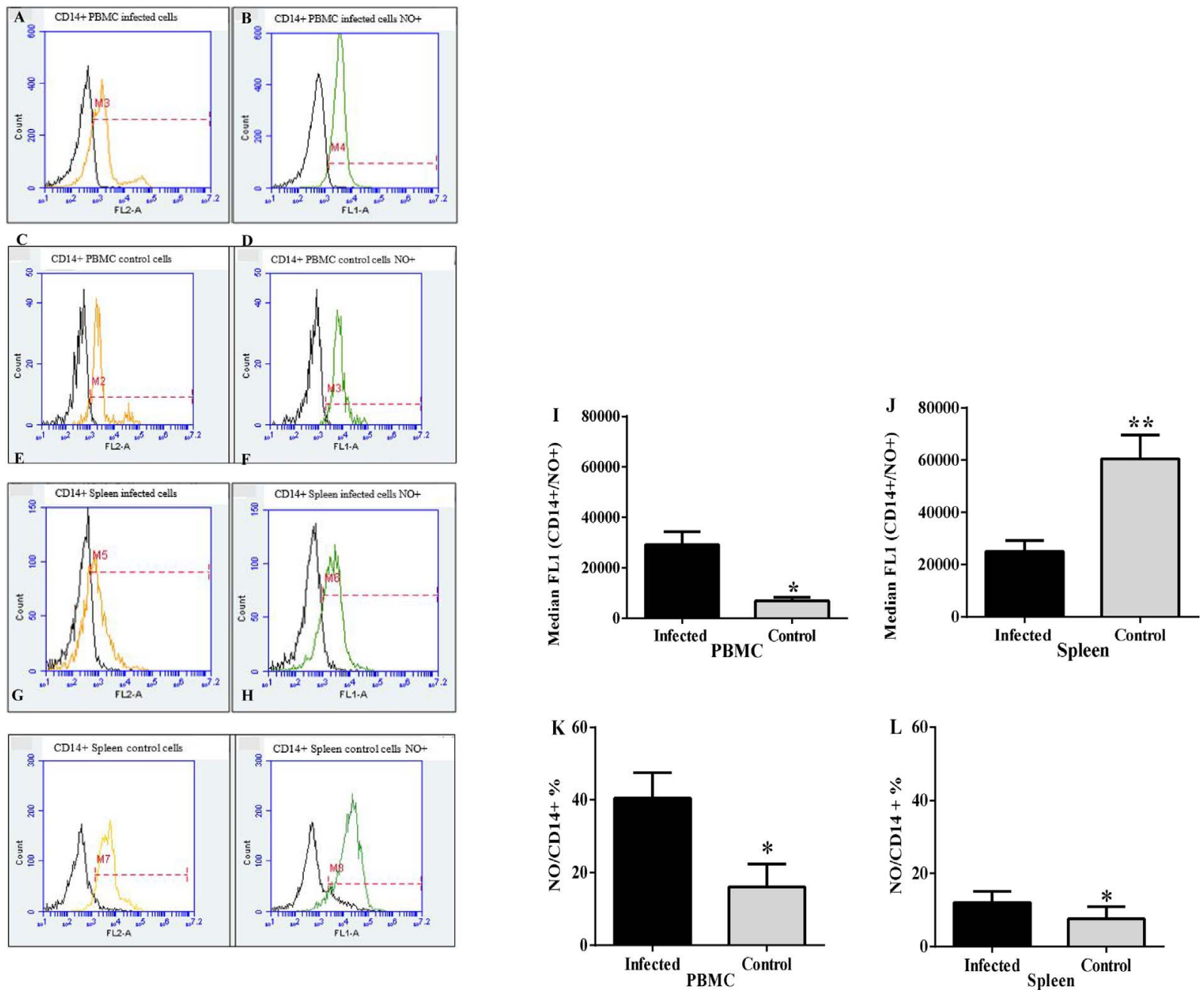

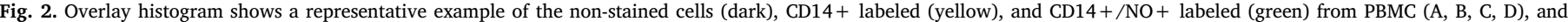

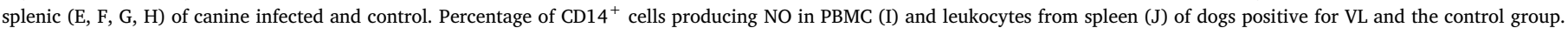

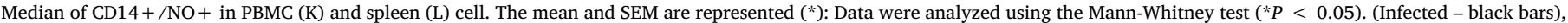
(Control - gray bars). (For interpretation of the references to colour in this figure legend, the reader is referred to the web version of this article.)

activation of caspases [17].

Although several of the apoptosis-inducing mechanisms have been studied in the canine VL, $[7,18,19]$, whether NO plays an important role in apoptosis and may contribute to the immunosuppression observed in canine VL has yet to be studied.

Measurement of the NO level in blood and tissue samples from canine VL has been performed indirectly as the quantification of iNOS [20] or the level of nitrate/nitrite in cell culture supernatants. The determination of NO has always been considered difficult due to its low concentration and its short half-life [21]. Many attempts to determine the level of NO have been undertaken using chemiluminescent tests, electrochemical electrodes, electron paramagnetic resonance spectroscopy and capture of NO with hemoglobin [22]. However, these methods do not identify the population analyzed and do not analyze intracellular events. [20] A probe used for detection of intracellular NO can provide more accurate information regarding the actual levels generated and can be linked to phenotypic markers for identifying the producer cells [23].

The objectives of this study were to quantify the level of NO produced by PBMC and leukocytes from spleen of VL symptomatic dogs and evaluate whether NO correlates with the cell apoptosis in these tissues and spleen parasite load.

\section{Material and methods}

\subsection{Approval of the ethics committee}

This study was approved by the Research Ethics Committee of Experimental Animals (COBEA) with approval of the Ethics Committee on Animal Use (CEUA) UNESP - Universidade Estadual Paulista "Julio de Mesquita Filho" - Campus Aracatuba - Faculty of Veterinary Medicine - FMVA - on 15/04/2011, as the process 00679/2011.

\subsection{Animals}

Twenty adult dogs of various breeds and weights, between two and five years old from the Zoonosis Control Center of Araçatuba were used for this study. These dogs diagnosed with VL were seropositive by ELISA assay [24] and positive to Leishmania by DNA detection in spleen samples using real time-PCR. All dogs were symptomatic and had at least three clinical signs of VL: 75\% had cachexia, 95\% onychogryphosis, 70\% lymphadenopathy, 70\% skin lesions, 30\% periocular alopecia, $30 \%$ alopecia and $33 \%$ other clinical signs.

The control group consisted of ten healthy dogs of various breeds and weights, all owners authorized the use of them for the experiment. The dogs were negative for anti-Leishmania spp. antibodies using ELISA [22] and negative for Leishmania DNA in spleen samples using real-time 

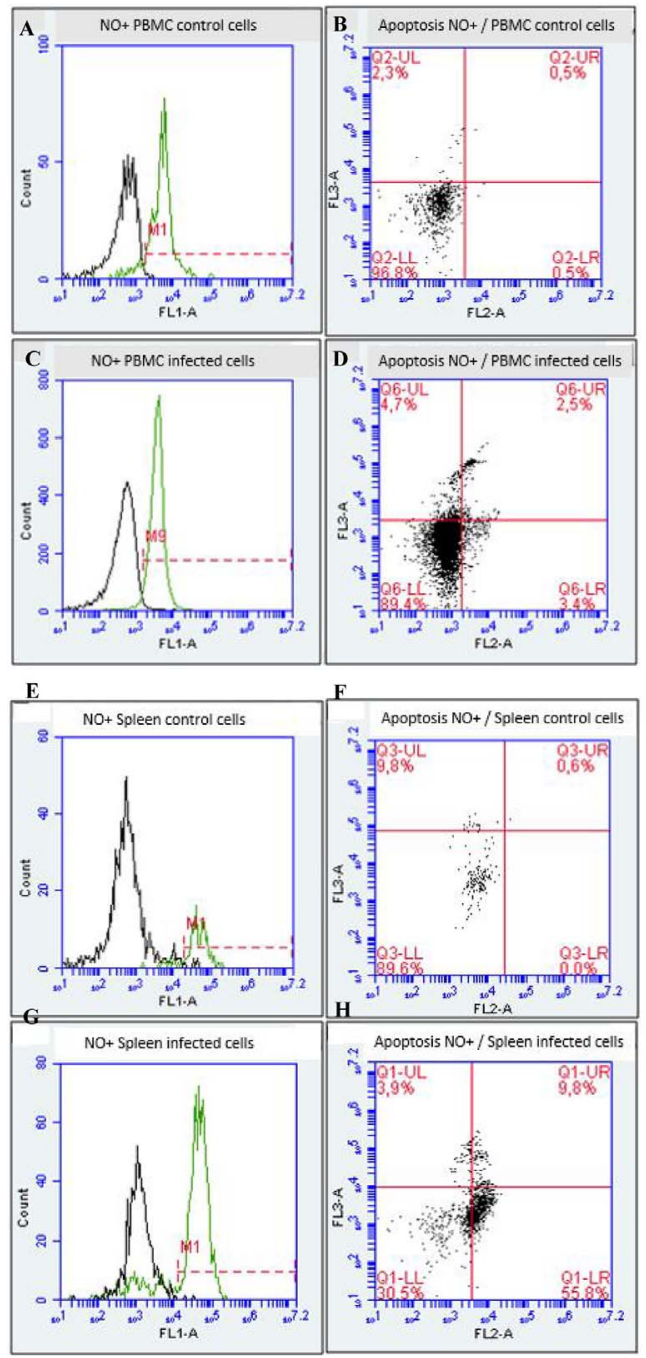
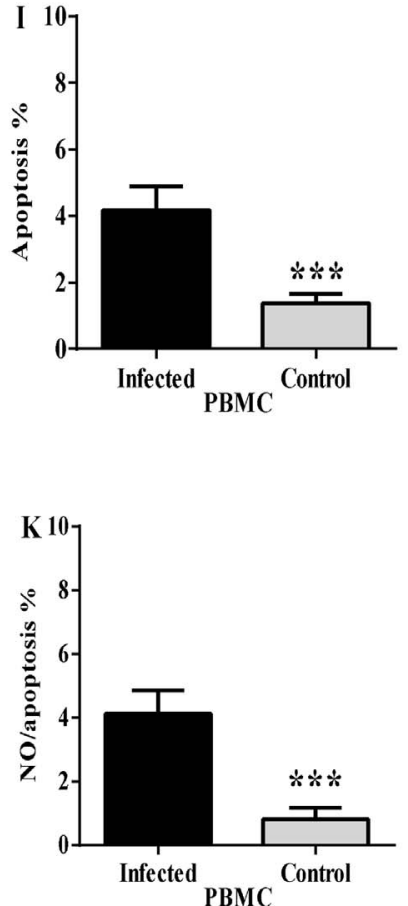
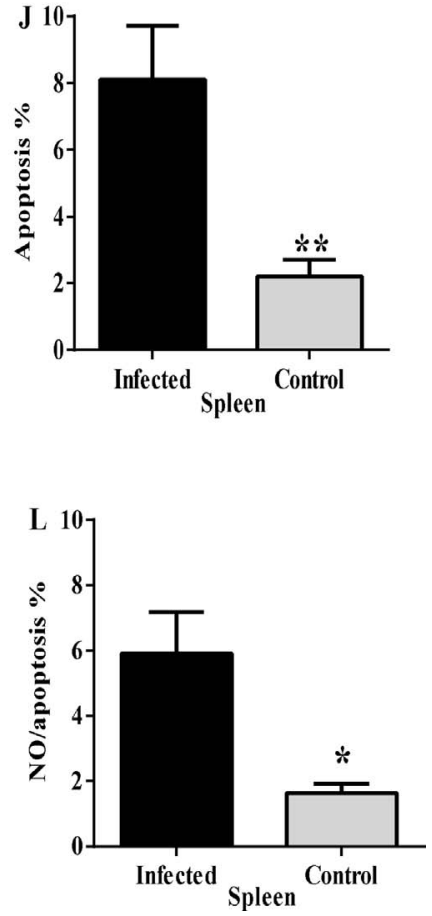

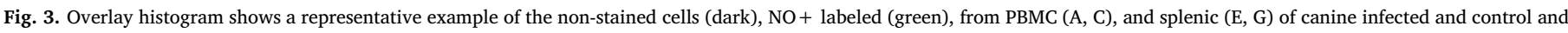

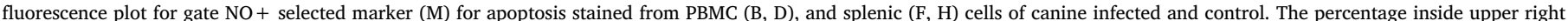

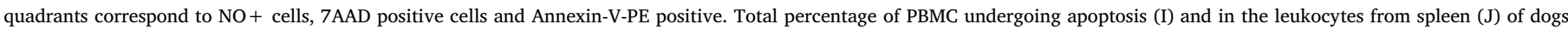

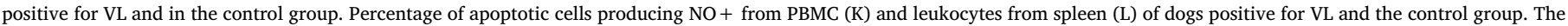

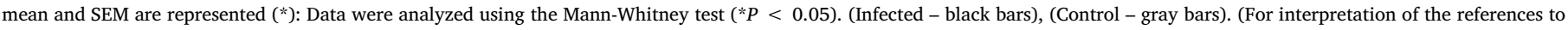
colour in this figure legend, the reader is referred to the web version of this article.)

PCR. All animals in the control group demonstrated blood counts within the reference values for the species, were fed with commercial feed and had unrestricted access to water.

\subsection{Collection of samples}

Dogs with VL were euthanized by intravenous injection of barbiturate anesthesia (thiopental, Cristália Itapira, SP) followed by $19.1 \%$ potassium chloride solution according to the 2006 São Paulo state law. After euthanasia, spleen fragments were collected and maintained in RPMI-1640 (Sigma *, USA) supplemented with 10\% heat inactivated fetal bovine serum (FBS) (Gibco, USA), 0.03\% L-glutamine (Sigma", USA), $100 \mathrm{IU} / \mathrm{mL}$ penicillin (Sigma ", USA) and $100 \mathrm{mg} / \mathrm{mL}$ streptomycin (Sigma ", USA). The blood samples from dogs with VL were obtained by intracardiac puncture and the control group blood samples were taken by jugular vein puncture. Samples were collected into tubes containing sodium heparin and were processed immediately after harvest.

Spleen samples from the control group were obtained by surgical excision using a protocol described by Lima et al. [2012].

\subsection{Isolation of mononuclear cells from peripheral blood leukocytes and the spleen}

The separation of mononuclear cells from peripheral blood was performed using Ficoll-Paque (Amersham Biosciences, Sweden) following the manufacturer's instructions. The isolated cells were washed three times in phosphate buffered saline (PBS, $\mathrm{pH} 7,2$ ), resuspended in RPMI-1640 (Sigma, St. Louis, MO, USA) supplemented as described above and maintained at $37{ }^{\circ} \mathrm{C}$ with $5 \% \mathrm{CO}_{2}$ (Revco, Waltham, MA, USA).

Splenic leukocytes were obtained by maceration of a fragment of spleen approximately $2 \mathrm{~cm}^{2}$ with the addition of $10 \mathrm{~mL}$ RPMI- 1640 (Sigma , USA) supplemented as previously described. After removal of cellular debris (BD Falcon Cell strainer, San Diego, CA, USA), the cell suspension was processed with $5 \mathrm{~mL}$ of red blood cell lysis buffer containing 7,46 g/L ammonium chloride $\left(\mathrm{NH}_{4} \mathrm{Cl}\right)$ and incubated at $4{ }^{\circ} \mathrm{C}$ for $10 \mathrm{~min}$, centrifuged at $2000 \mathrm{rpm}$ for $5 \mathrm{~min}$ at $20^{\circ} \mathrm{C}$, washed three times with PBS (pH 7,2) and suspended in a minimum volume of RPMI-1640 (Sigma, USA) supplemented as previously described. 


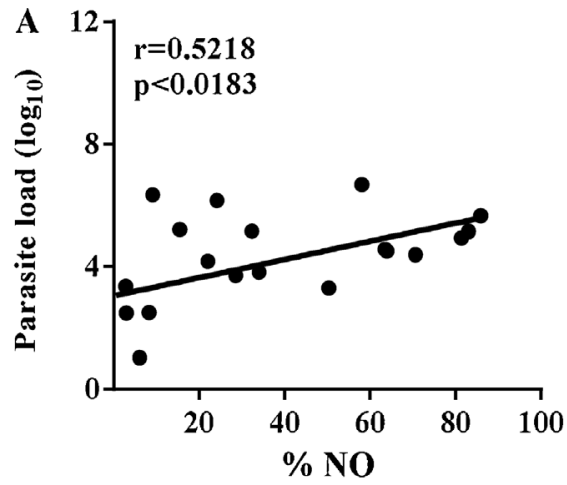

Fig. 4. (A) A significant positive correlation between the percentages of NO producing cells in the spleen with the parasite load observed in this tissue existed. (B) A significant positive correlation between $\mathrm{CD} 14^{+}$cells from the peripheral blood with the percentage of NO producing cells in this tissue existed. (C) A significant positive correlation between $\mathrm{CD} 14^{+}$ cells from the spleen with the percentage of NO producing cells in this tissue existed.

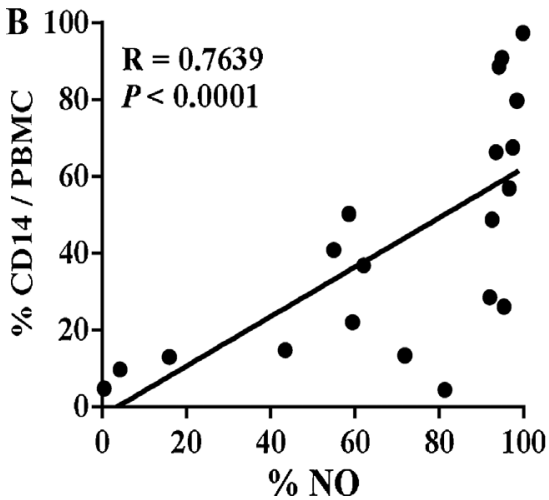

2.5. Immunostaining for intracellular CD14 and determination of nitric oxide level

Immunostaining for $\mathrm{CD} 14^{+}$cells was carried out on PBMC and splenic leukocytes with the addition of a PE-conjugated anti-CD14 monoclonal antibody (mouse IgG2a, clone TÜK4, AbDSerotec Oxford, UK). To quantify NO the same cell suspension was treated with DAF2DA $(2 \mu \mathrm{M})$ (Sigma-Aldrich, D225, São Paulo, Brazil) and incubated for 30 min at $37^{\circ} \mathrm{C}$ and $5 \% \mathrm{CO}_{2}$.

After labeling, samples were stored at $4{ }^{\circ} \mathrm{C}$ in the dark until analysis using the flow cytometer (BD Accuri ${ }^{\mathrm{TM}} \mathrm{C} 5$ Flow cytometer) and the acquired data were analyzed with BD Accuri ${ }^{\mathrm{TM}}$ C6 software (Version 1.0.264.21).

Cells $\left(1 \times 10^{6} / \mathrm{mL}\right)$ from different experimental groups were assessed for fluorescence in 10000 events counted using the flow cytometer (BD C5 Accuri flow cytometer, San Diego, CA, USA). Unlabeled samples were used as a negative control in order to delimit the negative populations in the samples. After exclusion of debris, cellular fluorescence of the triazole product (DAF-2T) was collected in the FL1 channel and the fluorescence of PE was collected in the FL2 channel. The median values of FL1 were used for the quantification of the amount of NO produced.

\subsection{The percentage of apoptotic cells and apoptotic cells $\mathrm{NO}^{+}$}

The Guava Nexin Assay kit (Millipore, USA) was used to determine the percentage of cells undergoing apoptosis following the manufacturer's instructions. Late apoptosis was determined using flow cytometry analysis with the fluorescence of PE-conjugated annexin $\mathrm{V}$ and 7AA-D, collected in the FL2 and FL3 channels, respectively.

The cellular fluorescence of the triazole product (DAF-2T) was collected in the FL1 channel and the gated population was analysis to determine apoptotic cells $\mathrm{NO}^{+}$.

\subsection{DNA extraction and real-time PCR}

DNA was extracted from $0.025 \mathrm{~g}$ of spleen samples using a commercial kit (DNeasy Qiagen, USA) according to the manufacturer's instructions. Quantification of the parasite load was determined using real-time PCR. The amplification of intergenic ITS1 of the parasite rRNA gene was performed using SYBR Green. The following temperature and cycles were used: initial heating at $94{ }^{\circ} \mathrm{C}$ for $2 \mathrm{~min}, 40$ cycles at $94^{\circ} \mathrm{C}$ for $15 \mathrm{~s}$, and a final extension at $60^{\circ} \mathrm{C}$ for $1 \mathrm{~min}$. After the amplification, dissociation curves of the amplified fragment were determined. For each reaction, a standard curve was generated with DNA from $L$. infantum promastigotes (MHOM/BR00/MER02) using dilutions of $10^{7}$ to $10^{3}$ parasites. The PCR showed a $\mathrm{R}^{2}=0.99$, Efficiency of 1.02 and Slope $=-3,2$.

\subsection{Statistical analysis}

After the data were classified as non-parametric using a test for normality. The comparison of the percentage of cells producing cells $\mathrm{NO}, \mathrm{CD} 14^{+}, \mathrm{CD}_{14}{ }^{+} / \mathrm{NO}^{+}$and cells undergoing apoptosis in the blood and spleen of the infected group to the control group was performed using the Mann-Whitney test. The results were considered to be significant when $P<.05$. Correlation analysis was performed using the Spearman test. Statistical analysis was performed and graphics were generated using GraphPad Prism 5 (GraphPad Software, Inc, CA, USA).

\section{Results}

\subsection{Determination of nitric oxide level}

Previous studies have shown that elevated expression of iNOS in macrophages is associated with a reduced number of amastigotes in the skin, lymph nodes and liver of dogs positive for VL [25], but in the spleen, iNOS expression was associated with clinical decline and high 
parasitism. [8] To verify that the dogs positive for VL were producing NO and its participation in the immune response to the infection, the level of NO producing cells in the blood and spleen of the positive dogs and control group dogs was determined, as well as the NO percentage produced by these cells.

Overlay histogram shows a representative example of the $\mathrm{NO}+$ labeled from PBMC, and splenic cells of canine infected and control respectively as shown in Fig. 1A-D. A higher level of NO was measured in the PBMC of dogs with VL compared to the controls $(P<.05)$; as shown in Fig. 1E; but a lower level of NO was measured in the leukocytes from spleen of dogs with VL (Fig. 1F). A higher percentage of cells producing NO in the PBMC and splenic leukocytes was observed in dogs with VL compared to the control group $(P<.05$; Fig. $1 \mathrm{G}$ and $\mathrm{H}$, respectively).

\section{2. $\mathrm{CD} 14^{+}$and $\mathrm{CD} 14^{+} / \mathrm{NO}^{+}$cells}

In order to characterize the cell producing NO, a probe was used for the intracellular detection of $\mathrm{NO}$ associated with $\mathrm{CD} 14^{+}$cells. Overlay histogram shows a representative example of the CD14+ and CD14+/ $\mathrm{NO}+$ labeled from PBMC, and splenic cells of canine infected and control respectively as shown in Fig. 2A-H. A higher level of CD14+/ $\mathrm{NO}+$ was measured in the PBMC of dogs with VL compared to the controls $(P<.05)$; as shown in Fig. 2I; but a lower level of NO was measured in the leukocytes from spleen of dogs with VL (Fig. 2J). The percentage of $\mathrm{CD} 14^{+} / \mathrm{NO}^{+} \mathrm{PBMC}$ and leukocytes from spleen of dogs with VL was higher compared to the control group $(P<.05)$, as shown in Fig. $2 \mathrm{~K}$ and L, respectively. An increase in $\mathrm{CD} 14^{+}$cells in the blood and spleen of dogs with VL compared to controls was also observed (data not shown).

\subsection{Cellular apoptosis, apoptotic cells $\mathrm{NO}^{+}$and correlation between apoptotic cells and NO}

Overlay histogram shows a representative example of the NO+ labeled from PBMC and splenic respectively and gated cells as NO+ were selected marker (M) for apoptosis as shown Fig. 3A-H. Apoptosis of PBMC and leukocytes from the spleen of dogs with VL was higher than the control group $(P<.05)$, as shown in Fig. 3I and $\mathrm{J}$; and apoptotic cells NO + of PBMC and leukocytes from the spleen of dogs with VL was higher than the control group $(P<.05)$, as shown in Fig. $3 \mathrm{~K}$ and L. There was no correlation between the NO levels and apoptosis (data not showed)

\subsection{Determination of parasite load and correlation with $\mathrm{NO}$ and $\mathrm{CD} 14^{+}$ cells}

In order to verify that the NO was acting as a leishmanicide, parasite burden was assessed and correlated with the production of NO. The data showed a positive correlation between the percentage of NO producing cells in the spleen with the parasite load observed in this tissue (Spearman $r=0.5218, P<.0183$ ) as shown in Fig. 4A.

The number of $\mathrm{CD} 14^{+}$cells from the PBMC showed a correlation with the percentage of NO producing cells (Spearman $\mathrm{r}=0.7639$, $P<.0001$ ), as shown in Fig. 4B, and similar results were observed in the spleen (Spearman $r=0.7153, P<.0004$ ), as shown in Fig. 4C.

\section{Discussion}

Our results showed that the frequency of NO producing cells, the number of $\mathrm{CD} 14^{+}$cells, cells undergoing apoptosis, $\mathrm{CD} 14^{+} / \mathrm{NO}^{+}$cells and NO producing cells undergoing apoptosis were increased in PBMC and leukocytes from spleen of dogs naturally infected with VL. In addition, a higher levels of NO was observed in peripheral blood mononuclear cells; however, NO was observed at lower levels in the spleen of dogs with VL.
The high frequency of cells producing NO observed in the spleen of dogs with leishmaniasis confirmed previous results in which higher proportions of cells producing iNOS were observed in dogs with leishmaniasis $[26,8]$ Conversely, the levels of NO were reduced in the spleen, suggesting that the leishmanicidal function is impaired, in fact symptomatic dogs showed lower iNOS mRNA expression than asymptomatic [27]. and high iNOS expression was observed in macrophages containing little or no amastigotes internalized in the liver samples, skin and lymph node of dogs with VL. [23] In our study, the NO levels was reduced in the spleen suggesting an relevant role of NO in parasite killing by this mechanism in symptomatic dogs.

This report is the first describing of the production of intracellular NO in PBMC and leukocytes from spleen of dogs with VL. Higher levels of NO in PBMC was measured from dogs with VL compared to controls. This finding is different from what has been reported in human patients with VL, where lower levels of NO were measured in monocytes from patients compared to controls [23]. This result suggests that although the immune response in humans has similarities with the dog, there are inherent species differences in immune response.

The percentage of cells undergoing apoptosis was higher in dogs with VL, confirming previous studies. $[6,7,16]$ However, an association between production of NO and increased apoptosis of PBMC cells and splenic leukocytes was not observed in dogs with VL in this study, suggesting that the process of cell death is triggered by other means as previously described, sFAS, sFASL and caspase- 3 are increased in splenic extracts from dogs infected with VL [7], and mFAS and mFASL levels were also increased in $\mathrm{CD} 4^{+}$and $\mathrm{CD} 8^{+} \mathrm{T}$ cells in the blood and splenic cells of dogs with VL. [16]

The frequency of $\mathrm{CD}_{14}{ }^{+}$cells, a phenotypic marker for canine macrophages [28], was higher in PBMC and spleen leukocytes of infected dogs confirming previous studies. An increase in $\mathrm{CD}_{14}{ }^{+}$cells was also observed in the peripheral blood of dogs with VL [29]. Indeed, these cells are increased during the infectious processes [30,31], including canine VL.

The use of an intracellular probe for detecting NO allowed for its quantification, while previous studies used iNOS for the detection of NO in dogs infected with VL in order to demonstrate the production of NO $[26,10,25]$. However, the detection of iNOS positive cells does not define NO levels, leading to inconclusive results. In our study, the intracellular detection of NO using a probe allowed evaluation the levels of production.

Detection of $\mathrm{CD}_{14} 4^{+} / \mathrm{NO}^{+}$cells was higher in PBMC and splenic leukocytes of positive dogs, and we showed a positive correlation between the $\mathrm{CD} 14^{+}$cells and the percentage of NO producing cells observed in the PBMC and splenic leukocytes of dogs with VL suggesting that this population could be the major producer of NO. In other studies, an increase in these cells was observed in the peripheral blood [11,29,12], colon and jejunum of dogs infected with VL [32].

A positive correlation was observed between the frequency of cells producing NO in the spleen and the parasite load. In fact, high expression of iNOS has been observed in the spleen of naturally infected symptomatic dogs associated with a high parasite load [10]. It is likely that the amount produced is insufficient to reduce splenic parasite burden. This finding suggests that other mechanisms might be involved in the death of the parasite such as the cytotoxic activity of $\mathrm{CD}^{+} \mathrm{T}$ cells that were present at elevated levels in the peripheral blood of dogs with reduced parasitic load after vaccination [33].

The lack of correlation between NO production in splenic macrophages and the parasitic load also was previously observed in the skin at where the increase of parasitic load led to upregulation of TLR2, IL10 and TNF but not iNOS [34], it can also be related to the evasive mechanisms of Leishmania used to suppress the production of NO in order to maintain their survival in the host and that may be damaging the leishmanicidal activity [35]. In addition, the high percentage of cells producing $\mathrm{NO}$ in the spleen in the apoptotic process would undermine the control of the parasitic load. 


\section{Conclusion}

The NO participates in the immune response in the canine VL, but possibly it is not apoptosis inducer.

\section{Conflict of interest}

We declare that we have no conflict of interest.

\section{Acknowledgment}

The authors would like to thank CAPES for granting a masters scholarship and the São Paulo Research Foundation, FAPESP (process 2013/06684-9) for funding the research.

\section{References}

[1] J. Alvar, I.D. Vélez, C. Bern, M. Herrero, P. Desjeux, J. Cano, J. Jannin, M. den Boer, WHO Leishmaniasis Control Team. Leishmaniasis worldwide and global estimates of its incidence, PLoS One 7 (2012) e35671.

[2] P.A.H. Organization, Leishmaniasis epidemiological report in the Americas, Leishmaniasis Report, Pan American Health Organization, Washington, 2018 PANAMERICAN HEALTH ORGANIZATION - PAHO/WHO - www.paho.org2017.

[3] E.H. Aarntzen, G. Schreibelt, K. Bol, W.J. Lesterhuis, A.J. Croockewit, J.H. de Wilt, M.M. van Rossum, W.A. Blokx, J.F. Jacobs, T. Duiveman-de Boer, et al., Vaccination with mRNA-electroporated dendritic cells induces robust tumor antigen-specific CD4 + and CD8 + T cells responses in stage III and IV melanoma patients, Clin. Cancer Res. 18 (2012) 5460-5470.

[4] J. Alencar, C.F. de Mello, N.M. Serra-Freire, A. Guimarães, H.R. Gil-Santana, R.M. Gleiser, Biodiversity and temporal distribution of immature culicidae in the Atlantic Forest, Rio de Janeiro State, Brazil, PLoS One 11 (2016) e0159240.

[5] C.C. Santana, J. Vassallo, L.A. de Freitas, G.G. Oliveira, L.C. Pontes-de-Carvalho, W.L. dos-Santos, Inflammation and structural changes of splenic lymphoid tissue in visceral leishmaniasis: a study on naturally infected dogs, Parasite Immunol. 30 (2008) 515-524.

[6] R.J. Slappendel, R. van Zwieten, M. van Leeuwen, C.T. Schneijdenberg, Hereditary spectrin deficiency in Golden Retriever dogs, J. Vet. Intern. Med. 19 (2005) 187-192.

[7] Institute Adolfo Lutz. Regional Laboratory Center of Araçatuba, SP. In: Canine visceral leishmaniasis inquiry data. http://www.ial.sp.gov.br/2016.

[8] V.M. Lima, M.E. Santiago, C. Lda Sanches, B.D. Lima, Molecular diagnosis of Leishmania amazonensis in a captive spider monkey in Bauru, São Paulo, Brazil, J. Zoo Wildl. Med. 43 (2012) 943-945.

[9] J. Perosso, K.L. Silva, S. Ferreira, S.V. Avanço, P.S. dos Santos, F. Eugênio, R. de, B.F. de Almeida, V.M. de Lima, Alteration of sFAS and sFAS ligand expression during canine visceral leishmaniosis, Vet. Parasitol. 205 (2014) 417-423.

[10] F.R. dos Santos, P.M. Vieira, R. Correa-Oliveira, R.C. Giunchetti, C.M. Carneiro, A.B. Reis, L.C. Malaquias, Qualitative and quantitative immunohistochemical evaluation of iNOS expression in the spleen of dogs naturally infected with Leishmania chagasi, Parasitol. Res. 108 (2011) 1397-1403.

[11] W. Coura-Vital, M.J. Marques, R.C. Giunchetti, A. Teixeira-Carvalho, N.D. Moreira, J. Vitoriano-Souza, P.M. Vieira, C.M. Carneiro, R. Corrêa-Oliveira, O.A. MartinsFilho, et al., Humoral and cellular immune responses in dogs with inapparent natural Leishmania infantum infection, Vet. J. 190 (2011) e43-47.

[12] A.B. Reis, A. Teixeira-Carvalho, R.C. Giunchetti, L.L. Guerra, M.G. Carvalho, W. Mayrink, O. Genaro, R. Corrêa-Oliveira, O.A. Martins-Filho, Phenotypic features of circulating leucocytes as immunological markers for clinical status and bone marrow parasite density in dogs naturally infected by Leishmania chagasi, Clin. Exp. Immunol. 146 (2006) 303-311.

[13] D. Menezes-Souza, R. Corrêa-Oliveira, R. Guerra-Sá, R.C. Giunchetti, A. TeixeiraCarvalho, O.A. Martins-Filho, G.C. Oliveira, A.B. Reis, Cytokine and transcription factor profiles in the skin of dogs naturally infected by Leishmania (Leishmania) chagasi presenting distinct cutaneous parasite density and clinical status, Vet. Parasitol. 177 (2011) 39-49.

[14] E. Pinelli, D. Gebhard, A.M. Mommaas, M. van Hoeij, J.A. Langermans, E.J. Ruitenberg, V.P. Rutten, Infection of a canine macrophage cell line with Leishmania infantum: determination of nitric oxide production and anti-leishmanial activity, Vet. Parasitol. 92 (2000) 181-189.
[15] M.A. Panaro, O. Brandonisio, D. de Caprariis, P. Cavallo, A. Cianciulli, V. Mitolo, D. Otranto, Canine leishmaniasis in Southern Italy: a role for nitric oxide released from activated macrophages in asymptomatic infection, Parasite Vectors 1 (2008) 10

[16] C. Bogdan, Nitric oxide and the immune response, Nat. Immunol. 2 (2001) 907-916.

[17] B. Brüne, Nitric oxide: NO apoptosis or turning it on, Cell Death Differ. 10 (2003) 864-869.

[18] K.L. Silva, L.M. Melo, J. Perosso, B.B. Oliveira, P.S. Santos, F.R. Eugênio de, V.M. Lima, CD95(FAS) and CD178 (FASL) induce the apoptosis of CD4 + and CD8 + cells isolated from the peripheral blood and spleen of dogs naturally infected with Leishmania spp, Vet. Parasitol. 197 (2013) 470-476.

[19] V.M. Chiku, K.L. Silva, B.F. de Almeida, G.L. Venturin, A.A. Leal, C.C. de Martini, F. de Rezende Eugênio, P.S. Dos Santos, V.M. de Lima, PD-1 function in apoptosis of T lymphocytes in canine visceral leishmaniasis, Immunobiology 221 (2016) 879-888.

[20] P. Failli, S. Nistri, S. Quattrone, L. Mazzetti, M. Bigazzi, T.B. Sacchi, D. Bani, Relaxin up-regulates inducible nitric oxide synthase expression and nitric oxide generation in rat coronary endothelial cells, FASEB J. 16 (2002) 252-254.

[21] F.L. Kiechle, T. Malinski, Nitric oxide. Biochemistry pathophysiology, and detection, Am. J. Clin. Pathol. 100 (1993) 567-575.

[22] J.Y. Chatton, M.C. Broillet, Detection of nitric oxide production by fluorescent indicators, Methods Enzymol 359 (2002) 134-148.

[23] A. Sarkar, P. Saha, G. Mandal, D. Mukhopadhyay, S. Roy, S.K. Singh, S. Das, R.P. Goswami, B. Saha, D. Kumar, P. Das, M. Chatterjee, Monitoring of intracellular nitric oxide in leishmaniasis: its applicability in patients with visceral leishmaniasis, Cytometry A 79 (2011) 35-45.

[24] V.M. Lima, M.E. Gonçalves, F.A. Ikeda, M.C. Luvizotto, M.M. Feitosa, AntiLeishmania antibodies in cerebrospinal fluid from dogs with visceral leishmaniasis, Braz. J. Med. Biol. Res. 36 (2003) 485-489.

[25] R. Zafra, J.R. Jaber, R.A. Pérez-Ecija, A. Barragán, A. Martínez-Moreno, J. Pérez, High iNOS expression in macrophages in canine leishmaniasis is associated with low intracellular parasite burden, Vet. Immunol. Immunopathol. 123 (2008) $353-359$.

[26] F.P. Sanches, T.Y. Tomokane, V.L. Da Matta, M. Marcondes, C.E. Corbett, M.D. Laurenti, Expression of inducible nitric oxide synthase in macrophages inversely correlates with parasitism of lymphoid tissues in dogs with visceral leishmaniasis, Acta Vet. Scand. 56 (2014) 57.

[27] M. Nascimento, T. Albuquerque, A. Nascimento, I.S. Caldas, M.A. Do-Valle-Matta, J.T. Souto, A. Talvani, M.T. Bahia, L.M. Galvão, A.C. Câmara, P.M. Guedes, Impairment of interleukin -17A expression in canine visceral leishmaniosis is correlated with reduced interferon-ã and inducible nitric oxide synthase expression, J Comp. Pathol. (2015) 197-205.

[28] H. Daneshvar, F. Sedghy, S. Dabiri, H. Kamiabi, M.M. Molaei, S. Phillips, R. Burchmore, Alteration in mononuclear cell subpopulations in dogs immunized with gentamicin-attenuated Leishmania infantum, Parasitology 139 (2012) 1689-1696.

[29] G.G. de Almeida Leal, B.M. Roatt, R.D. de Oliveira Aguiar-Soares, C.M. Carneiro, R.C. Giunchetti, A. Teixeira-Carvalho, O.A. Martins-Filho, A.F. Francisco, J.M. Cardoso, et al., Immunological profile of resistance and susceptibility in naturally infected dogs by Leishmania infantum, Vet. Parasitol. 205 (2014) 472-482.

[30] G. Fingerle, A. Pforte, B. Passlick, M. Blumenstein, M. Ströbel, H.W. ZieglerHeitbrock, The novel subset of CD14 +/CD16 + blood monocytes is expanded in sepsis patients, Blood 82 (1993) 3170-3176.

[31] W.A. Nockher, J.E. Scherberich, Expanded CD14+ CD16 + monocyte subpopulation in patients with acute and chronic infections undergoing hemodialysis, Infect. Immun. 66 (1998) 2782-2790.

[32] M.M. Figueiredo, I.F. Amorim, A.J. Pinto, V.S. Barbosa, Pinheiro LeJ, B. Deoti, A.M. Faria, W.L. Tafuri, Expression of Toll-like receptors 2 and 9 in cells of dog jejunum and colon naturally infected with Leishmania infantum, BMC. Immunol. 14 (2013) 22.

[33] R.D. Aguiar-Soares, B.M. Roatt, H.G. Ker, N. Moreira, F. A. Mathias, J.M. Cardoso, N.F. Gontijo, O. Bruna-Romero, A. Teixeira-Carvalho, O.A. Martins-Filho, et al., LBSapSal-vaccinated dogs exhibit increased circulating T-lymphocyte subsets (CD4 and $\mathrm{CD}^{*}$ ) as well as a reduction of parasitism after challenge with Leishmania infantum plus salivary gland of Lutzomyia longipalpis, Parasite Vectors 7 (2014) 61.

[34] D.C.M. Pereira-Fonseca, F.M. Oliveira-Rovai, L.A.C. Rodas, C.A.C. Beloti, R.B.P. Torrecilha, Ito PKRK, S.V. Avanço, R.S. Cipriano, Y.T. Utsunomiya, R.M. Hiramoto, et al., Dog skin parasite load, TLR-2, IL-10 and TNF- $\alpha$ expression and infectiousness, Parasite Immunol. 39 (2017).

[35] M.E. Wilson, S.M. Jeronimo, R.D. Pearson, Immunopathogenesis of infection with the visceralizing Leishmania species, Microb. Pathog. 38 (2005) 147-160. 